\title{
HiNCHE: TERRITORIO dE PAZ, CENTRO DE SABERES CAMPESINOS. CAMINANDO LA UTOPÍA
}

Twentieth century pedagogical heritage, protecting a cultural inheritance: The Castelló Education Museum and its conservation and restoration work

\author{
Miguel Antonio Rodríguez Suárez \\ Fundación Universitaria Monserrate, Bogotá (Colombia) \\ miguelrodriguezsuarez08@gmail.com \\ https://orcid.org/0000-0002-9115-7155
}

RESUMEN: El artículo realiza, desde el paradigma crítico social y desde el tipo de investigación de sistematización de experiencias, una contextualización sociogeográfica de Colombia en donde también aparecen algunos aspectos sociohistóricos que permiten poner en el centro de la discusión la importancia de la tenencia de la tierra que ha generado diversas disputas en donde se han identificado intereses externos e internos al país.

Este punto se convierte en el eje de inflexión, en donde a pesar de las diferentes fuerzas en tensión, se recupera y visibiliza la experiencia de un grupo de mujeres campesinas que forjan paz en, desde, por y para su territorio, donde han logrado, a través de sus propios saberes, la reconstrucción del tejido social y la recuperación de los espacios comunitarios que fueron en su momento arrebatados por los diferentes grupos armados en medio del colapso parcial del Estado. Una experiencia de paz positiva, que según De Roux (2018) es “al mismo tiempo limitada, vulnerable, criticable. Apoyarla es un acto de audacia, no de temeridad; es un acto moral, porque el país vive momentos de incertidumbre" (11).

Palabras clave: Saberes campesinos, memoria colectiva, colapso parcial del Estado, Paz.

ABSTRACT: This paper takes a socio-critical perspective to offer a socio-geographical contextualization of Colombia. The research is based on a systematization of experiences and reveals some socio-historical aspects that point to the importance of placing land tenure at the heart of the debate, a topic that 
has generated disputes where external as well as domestic interests have been identified.

This issue has become the turning point where, despite a climate of tension among various forces, the experience of a group of peasant women working together for peace (in, from, by, and for their territory) is recovered and made visible. Through their own knowledge, they have reconstructed the social fabric and the recovery of community spaces that had been taken away by different armed groups during the partial collapse of the State. This is a positive peace experience that, according to De Roux (2018) is "at the same time limited, vulnerable, open to criticism. Supporting it is an act of audacity, not recklessness; it is a moral act because the country is living moments of uncertainty" (11).

KeYwords: Peasant knowledge, collective memory, partial collapse of the State, Peace.

RESUM: L'article realitza, des del paradigma crític social i des del tipus d'investigació de sistematització d'experiències, una contextualització sociogeogràfica de Colòmbia on també apareixen alguns aspectes sociohistòrics que permeten posar en el centre de la discussió la importància de la tinença de la terra que ha generat diverses disputes on s'han identificat interessos externs i interns al país. Aquest punt es converteix en l'eix d'inflexió, on malgrat les diferents forces en tensió, es recupera i visibilitza l'experiència d'un grup de dones llauradores que forgen pau en, des de, per i per al seu territori, on han aconseguit, a través dels seus propis sabers, la reconstrucció del teixit social i la recuperació dels espais comunitaris que van ser en el seu moment arrabassats pels diferents grups armats enmig del col-lapse parcial de l'Estat. Una experiència de pau positiva, que segons De Roux (2018) és "al mateix temps limitada, vulnerable, criticable. Secundar-la és un acte d'audàcia, no de temeritat; és un acte moral, perquè el país viu moments d'incertesa" (11).

Paraules Clau: Sabers llauradors, memòria col-lectiva, col·lapse parcial de l'Estat, Pau. 


\section{Paz positiva en medio de la guerra en Colombia}

$\mathrm{E}$

n el marco de la guerra en Colombia, el cual ha estado caracterizado por espirales de violencia que se han registrado de manera histórica desde el siglo XV hasta la actualidad, han sido diversas las afectaciones en las dimensiones: sociales, económicas, políticas, culturales y ambientales, comprendiendo de esta manera, que más que un conflicto interno colombiano como se le ha querido denominar, la situación de guerra en Colombia es el resultado de intereses tanto externos por parte de diferentes países como por situaciones internas del país como lo son "las relaciones entre narcotráfico, actores armados organizados no estatales y estatales, e impactos humanitarios, que han sido marcadas desde finales de los 70 hasta el presente" (Defensoría del Pueblo, 2018, 30), que confluyen en un territorio en permanente disputa y que parecieran configurar una economía de guerra según lo sugerido por Goodhand (2003).

Este artículo, surge como resultado de la sistematización de experiencias de la tesis denominada: "Saberes campesinos que forjan territorios de paz en medio del colapso parcial del Estado en Colombia. Memoria colectiva en las veredas Hinche Alto e Hinche Bajo del Municipio de La Palma-Cundinamarca a través de las voces de campesinas y campesinos que tejen paz" ; la cual tiene como objetivo sistematizar los saberes campesinos que perviven en las Veredas Hinche Alto e Hinche Bajo del Municipio de La Palma-Cundinamarca por medio de un proceso de memoria colectiva para la construcción de territorios de paz en Colombia en medio del colapso parcial del Estado,

en el sentido que mientras algunos aparatos estatales (por ejemplo, la burocracia, la tecnocracia, la administración y los órganos de representación política) mantienen cierta coherencia y capacidad de acción, otros cruciales aparatos del Estado se han vuelto incapaces de cumplir sus funciones y prestar los servicios para los que han sido diseñados (entre ellos, los casos más notables son la seguridad y la justicia), o se han desfigurado totalmente con respecto a sus funciones constitucionales (por ejemplo, las Fuerzas Armadas). (Bejarano y Pizarro, 2010, 388) 
El proceso de sistematización tiene como antecedente el año 2017, cuando por un convenio entre el Consejo Nacional para la Educación en Trabajo Social (CONETS) y la Unidad de Atención y Reparación Integral a las Víctimas (UARIV), se define acompañar a 10 poblaciones víctimas de la guerra que han sido reconocidas por medio de la Ley 1449 de 2011 como Sujetos de Reparación Colectiva, entre el que se encuentra el Sujeto de La Palma-Cundinamarca. Este proceso fue denominado: Sujetos de Reparación Colectiva y Construcción de Territorios de Paz en el marco de la Ley 1448 de 2011 y tuvo como eje de sistematización el analizar la implementación de la estrategia entrelazando que se contempla dentro de las medidas de reparación colectiva.

El acompañamiento desde el año 2017 a la comunidad de las veredas Hinche Alto e Hinche Bajo del municipio de La Palma-Cundinamarca inició con esta primera pesquisa en relación a la estrategia entrelazando, que con el trasegar de la experiencia, fue permitiendo develar un nuevo eje de sistematización en torno a los saberes campesinos que tejen paz en medio del colapso parcial del Estado, pues "las preguntas o ejes temáticos iniciales planteados en el taller de diseño de la sistematización, se ratifican o modifican a lo largo del proceso de reconstrucción de la experiencia; lo que implica una sensibilidad para identificar” (Barragán y Torres, 2017, 91).

Así, la sistematización es entendida como una metodología:

participativa de investigación sobre prácticas significativas de transformación social o educativa, que, a partir de su reconstrucción narrativa e interpretación crítica de las lógicas y los sentidos que la constituyen, busca potenciarlas y producir saberes que aportan a las resistencias y re-existencias frente al modelo hegemónico. (Barragán y Torres, 2017, 49)

Desde esta perspectiva, las campesinas y los campesinos de las veredas Hinche Alto e Hinche Bajo hacen parte del proceso investigativo de manera dialógica como "concepción que parte de las actuaciones contextualizadas de los diferentes actores sociales y de las interacciones que se producen, entendidas como generadoras de conocimiento" (Elboj y Gómez, 2001, 77). Así, se conforma el colectivo sistematizador, el cual consiste en "delegar a algunas personas de la organización para que hagan parte [...], definir espacios de 
encuentro para acordar los sentidos de la sistematización y decidir un cronograma en el que además de los delegados del equipo sistematizador, participen distintos actores" (Barragán y Torres, 2017, 88), en donde se debate a través de consensos y disensos con las participantes, aquello que emerge de las memorias colectivas en lo correspondiente a la vivencia de la guerra y sus apuestas en torno a la paz.

Dicho proceso de recuperación de la memoria colectiva en la población campesina con la que se realiza esta sistematización de experiencias ha sido posible a través de encuentros grupales con técnicas como lo son: la cartografía social que consiste en plasmar en mapas los lugares comunitarios que fueron afectados por la guerra siendo recuperados y transformados por la comunidad; de igual manera, a través de la técnica, sabores y saberes en donde se prepara la comida tradicional de la región y a la vez se recuperan aquellos recuerdos históricos que perviven de manera colectiva en la población en perspectiva de construcción de paz.

De esta manera, las memorias colectivas surgen tal como sostiene Halbwacsh (citado en Méndez, 2008), de "cualquier recuerdo, que aunque sea muy personal, existe en relación con un conjunto de nociones que nos dominan más que otras, con personas, grupos, lugares, fechas, palabras y formas de lenguaje incluso con razonamientos e ideas, es decir, con la vida material y moral de las sociedades que hemos formado parte" (38), que en este caso en particular, se vincula desde las subjetividades de un grupo de mujeres campesinas que tejen vida en medio de los avatares de la guerra vivida en las veredas Hinche Alto e Hinche Bajo del municipio de La Palma en el departamento de Cundinamarca, donde es posible:

[...] amar, vivir, sonreír, compartir; donde los vínculos, son cómplices de cada uno de estos sentimientos propios de las relaciones humanas, ya que fortalecen la unión entre individuos y forjan lazos de empatía; los cuales, son transmitidos desde diferentes tipos de lenguajes y/o acciones de expresión. (Arévalo, Bernal, Quiñones, Rodríguez y Tarazona, 2018, 19)

A partir de estos logros y de este grito de esperanza en medio del caos y la confusión, es que en el último apartado, se comparte la utopía que se camina en la actualidad en esta zona campesina de Colombia. Un caminar la utopía a partir de lo que Eduardo Galeano periodista y escritor uruguayo expresa de 
la siguiente manera: "la utopía está en el horizonte. Camino dos pasos, ella se aleja dos pasos y el horizonte se corre diez pasos más allá. Entonces, para qué sirve la utopía? Para eso, sirve para caminar".

\section{Contextualización sociogeográfica}

En Colombia, el abordar el tema de la guerra y de la paz ha ido tejiendo un vínculo estrecho con lo que implica la tierra así como su tenencia; es por ello, que en el proceso investigativo el diálogo entre elementos geográficos y sociales ha recobrado una relevancia significativa, considerando necesaria una contextualización partiendo de lo general a lo particular, para referenciar lo que en Colombia significa lo rural, que se configura en los espacios campesinos que se circunscriben al interior de los departamentos que son entidades territoriales

de primer nivel de la división político-administrativa del Estado que agrupa municipios y áreas no municipalizadas. Goza de autonomía para la administración de los asuntos seccionales y la planificación y promoción del desarrollo económico y social dentro de su territorio en los términos establecidos por la Constitución y las leyes." (Departamento Administrativo de Estadística , 2018, 11).

Estos departamentos se componen de municipios que son una "entidad territorial fundamental de la división político-administrativa del Estado, con autonomía política, fiscal y administrativa dentro de los límites que le señalen la Constitución y las leyes de la República" (Departamento Administrativo Nacional de Estadística, 2018, 12). A su vez, los municipios se configuran por dos denominaciones territoriales, las cabeceras municipales que son una “delimitación geográfica definida por el DANE para fines estadísticos, alusiva al área geográfica delimitada por el perímetro censal. A su interior se localiza la sede administrativa del municipio, es decir, la alcaldía" (Departamento Administrativo Nacional de Estadística, 2018, 11); y las veredas, que se conciben como una "división territorial de carácter administrativo en el área rural de los municipios, establecida mediante acuerdo municipal. Se concibe como una agrupación comunitaria de base territorial y principal espacio de sociabilidad, caracterizada por el predominio de las relaciones vecinales". (Departamento Administrativo Nacional de Estadística, 2018, 13). 
El país se encuentra ubicado en el continente americano, el cual está en el hemisferio occidental del globo terráqueo, caracterizándose por ser el segundo continente más grande del planeta después de Asia “debido a su gran tamaño y sus características geográficas [...], según las características culturales se distingue América Anglosajona, el Caribe no latino y América Latina. Se utiliza también el término las Américas para referirse a la totalidad de las subregiones". (Benseny, 2020, 1)

Así, dentro de las Américas, se podría decir que Colombia por cercanía lingüística y cultural se relaciona intrínsecamente con dos de ellas; por un lado en lo que se ha referenciado como América Latina o Latinoamérica (20 naciones), que la vincula con los diferentes países de la región que tienen un idioma que deriva del latín y que principalmente cubre desde la zona norte con los Estados Unidos Mexicanos hasta el extremo sur del continente con la República de Argentina, agremiando tanto los países que se encuentran en la plataforma continental, como aquellos que se ubican en islas del caribe que en medio de su pluriversalidad y complejidad, refleja un contexto convulso como lo plantea Cepeda:

[...] es válido hacerse preguntas sobre el rumbo de los procesos de integración y la democratización de los Estados latinoamericanos. Si bien los procesos de regionalismo abierto intentaron fomentar la democracia, no es muy claro qué tipo de democracia es la que algunos Estados suramericanos buscarían fomentar a partir de procesos como PROSUR (Cepeda, 2019, 364)

Por otro lado, pertenece a América del Sur conformada por 13 países que comprende desde la República de Colombia en la parte norte hasta la República de Argentina en la zona sur, caracterizada por su diversidad en flora y fauna, pues posee " las formaciones geológicas más antiguas del planeta; a su estructura hidrográfica, en ella se encuentra el río más caudaloso del mundo y el manto freático más grande del planeta [...] varios países tienen los ecosistemas más biodiversos y extensos de la tierra" (UNISDR, 2015, 2). En contraste con la riqueza de flora y fauna que se circunscribe en América del Sur, se presentan diferentes problemáticas como lo expondría en su momento Eduardo Galeano en su libro Las Venas Abiertas de América Latina (1971) en dimensiones: demográficas, ambientales, políticas, entre otras, debido: 
[...] a sus grandes ciudades, es la región con más alto índice de urbanización del mundo y de alta densidad poblacional; y en especial a su vulnerabilidad, presenta elevados niveles de inequidad y pobreza; estas condiciones tipifican a América del Sur como una de las regiones del mundo con un gran potencial de desarrollo y a la vez donde se configuran condiciones de exposición y vulnerabilidad [...]. Los niveles de pobreza y pobreza extrema, la inequidad de acceso a oportunidades y recursos en la región implican que estas amenazas afecten de manera diferenciada a ciertos segmentos de la población. Las presiones sobre la agricultura, ganadería y recursos naturales han llevado además a procesos migratorios rurales-urbanos y niveles de crecimiento y expansión urbana no adecuadamente planificada o con asentamientos precarios. (UNISDR, 2015, 2)

$\mathrm{Y}$ es precisamente en este entorno con características sociogeográficas expuestas con anterioridad, donde se configura la experiencia de campesinas y campesinos de Colombia que tejen paz a la luz de diversas luchas inscritas en América Latina referidas por Blanca Rubio entre las que se encuentran: las Ligas Camponesas en Brasil, la Unión de Ligas Campesinas Fomoseñas en Argentina, el movimiento dirigido por Hugo Blanco en Perú, la Federación Campesina en Venezuela, el movimiento de José Rojas en Bolivia, la defensa de la economía campesina en Colombia; entre otras, que históricamente han develado que:

La resistencia campesina e indígena de la región ha subido de tono. A los ancestrales agravios enfrentados por la población rural del continente, se han sumado la codicia y la rapiña sobre los recursos naturales asentados en las comunidades, al fragor de la crisis de fase del capital que ha engendrado nuevos monstruos. (Rubio, 2017, 15)

En medio del contexto social referido con anterioridad, geográficamente el país limita de manera terrestre al norte con el Mar Caribe y Panamá, al oriente con Brasil y Venezuela, al occidente con el Océano Pacífico, al sur con Ecuador y Perú. También posee fronteras marítimas por el pacífico con: Ecuador, Costa Rica y Panamá; y por el Caribe, con Costa Rica, Haití, Honduras, Jamaica, Nicaragua, Panamá, República Dominicana y Venezuela (ver figura1), tal como lo refiere la Oficina de Información Diplomática (2021): 
Colombia se ubica en el extremo noroccidental de América del Sur, con una superficie de $1.141 .748 \mathrm{Km}^{2}$, tiene costas en el Pacífico y en el Atlántico. Atravesada de Sur a Norte por los Andes que, cerca de la frontera meridional se dividen en tres ramales: cordilleras Occidental, Central y Oriental. Al Este de la cordillera Oriental se encuentra la Orinoquía o los Llanos, y la Amazonía colombiana. Aparte de los Andes: Serranía del Baudó y Sierra Nevada de Santa Marta. (2)

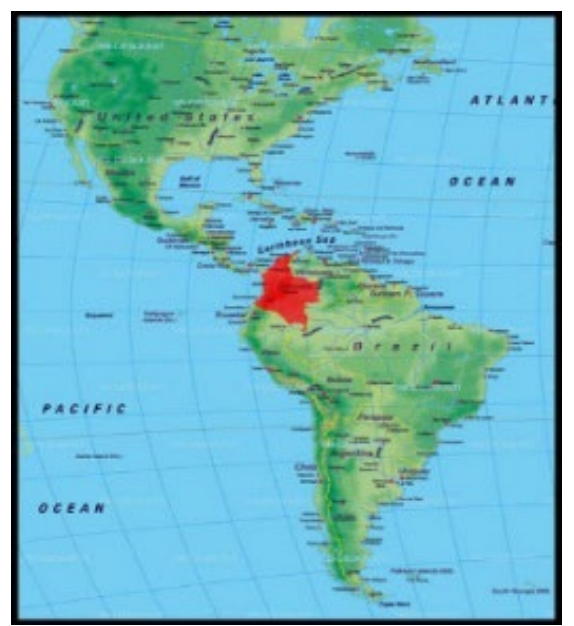

Figura 1. Mapa Político de América y ubicación de Colombia Recuperado de: http://solar.physics.montana.edu/munoz/AboutMe/ColombianMusic/Intro/Espanol_Donde.html.

Recuperando lo expuesto por la Oficina de Información Diplomática, la República de Colombia se encuentra divida políticamente en 32 departamentos (ver figura 2) y 5 distritos que se ubican en las ciudades de: Bogotá (Distrito Capital), Cartagena (Distrito Turístico y Cultural), Barranquilla (Distrito Especial), Santa Marta (Distrito Turístico, Cultural e Histórico) y Buenaventura (Distrito Especial, Industrial Portuario, Biodiverso y Ecoturístico). Como se había mencionado anteriormente, los departamentos están constituidos por municipios que suman a nivel nacional un total de 1123 , dentro de los que se encuentra el municipio de La Palma en el departamento de Cundinamarca.

La población proyectada en el país para el 2021 por el DANE es de 51.049.498 habitantes, de los cuales 7.834.167 que equivale al 15,34\% de la población total, se encuentra en la capital del país: Bogotá, sin contar con 
municipios que se encuentran aledaños a la ciudad, como es el caso de Soacha donde según la proyección del DANE para el 2020 cuenta con 753.548 habitantes con un alto porcentaje de población desplazada y afectada por la guerra. En el global de lo que se denominan cabeceras habitan 38.897 .845 personas que representan al 76,19\% del total de la población, ocupando el $0,3 \%$ del territorio nacional.

En centro poblado y rural disperso el cual es "una concentración mínima de veinte viviendas contiguas, vecinas o adosadas entre sí, ubicada en el área resto municipal o en un área no municipalizada (corregimiento departamental)" (DANE, 2018, 11), habitan 12.151.653 personas lo que equivale al 23,8\% de la población total del país distribuida en el 99,6\% del territorio, como lo afirma el Instituto Geográfico Agustín Codazzi (citado en Rodríguez, Albarracín, Jiménez y Vargas, 2021): “tan solo el 0,3 por ciento de todo el territorio colombiano es área urbana; el 99,6 por ciento restante está "pintado de verde", ya que está conformado por zonas rurales" (82-83), configurando así una concentración demográfica en las zonas urbanas quedando deshabitadas las rurales (ver figura 3), trayendo consigo el progresivo abandono del trabajo de la tierra, siendo la principal fuente del país al considerarse una nación donde su economía procede principalmente de lo agrario:

Colombia posee ventajas estratégicas para el comercio, el turismo y la habitabilidad, por encontrarse en una zona intertropical relativamente estable y tener una ubicación geoestratégica con costas en dos océanos, todos los pisos térmicos, gran biodiversidad y variedad de población. Sin embargo, esto se relativiza con los problemas estratégicos del paso de fenómenos naturales y socioculturales, eventos geológicos y ambientales y diferendos económicos y políticos que le afectan. (Barrero, 2017, 24)

Esta concentración de población en las cabeceras, se ha dado a causas de múltiples factores, rescatando en esta oportunidad como el más relevante, la guerra histórica que ha vivenciado el país; y de la cual según la Unidad de Atención y Reparación Integral a las Víctimas (UARIV), se han registrado 9.189.498 personas como víctimas, sin dejar de mencionar el proceso migratorio de población hermana de Venezuela, que según datos de Migración Colombia para enero de 2021 podría ser de 1.742.000. 


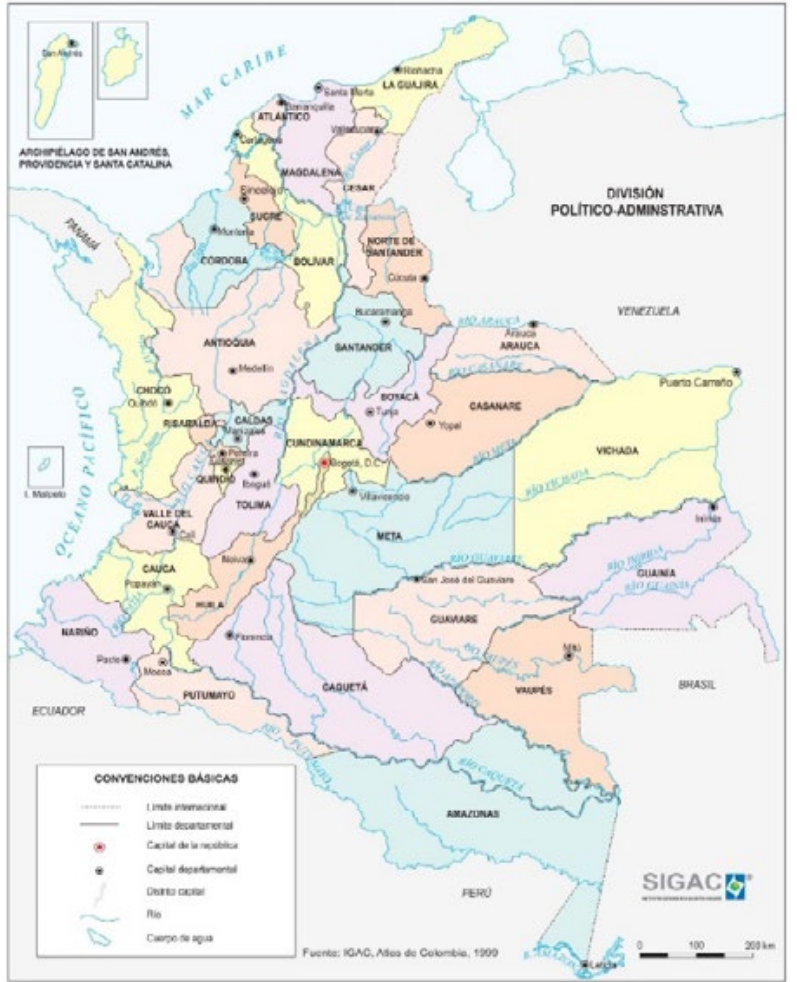

Figura 2. Mapa político de Colombia.

Recuperado de: Instituto Geográfico Agustín Codazzi (2021). https://geoportal.igac.gov.co/sites/geoportal.igac.gov.co/files/geoportal/politicoseg.pdf

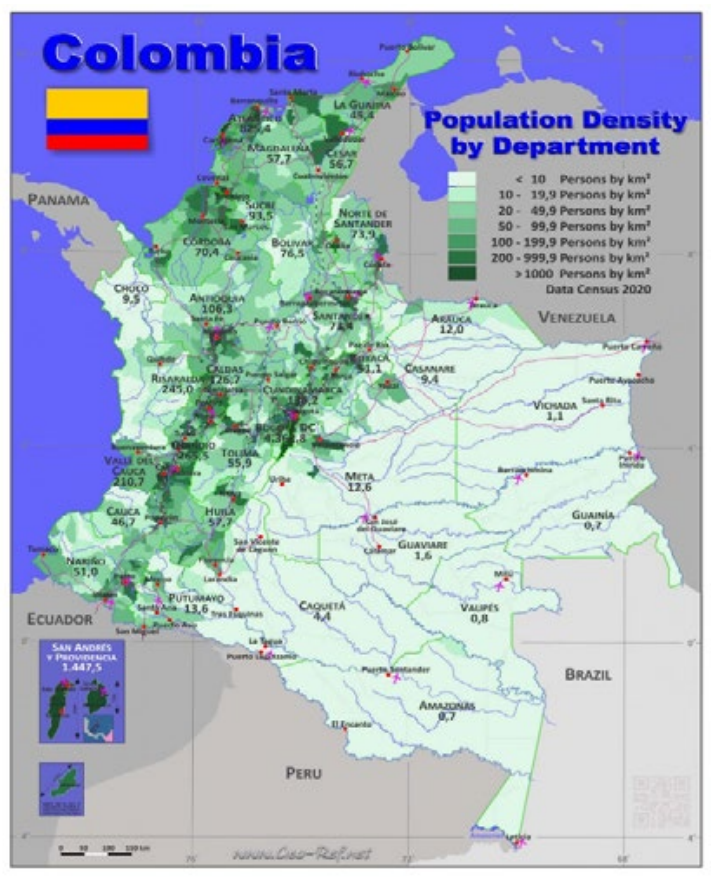

Figura 3. Densidad de Población.

Recuperado de: http://www.geo-ref.net/sp/col.htm 
Tal como se refiere en la figura anterior, el municipio de La Palma, se encuentra hacia el extremo noroccidental en el departamento de Cundinamarca el cual se ubica en el centro del país y cuenta con 116 municipios. Estos 116 municipios están repartidos en 15 provincias (ver figura 4), las cuales son "relevantes para el estudio de los patrones de ruralidad, ya que impulsan una concepción territorial por encima de la administración y provisión de los servicios públicos y más hacia la provisión de herramientas y modos de generación de ingreso, conocimiento" (Ramírez y De Aguas, 2016, 11). La región de Rionegro se encuentra a 150 Kilómetros con Bogotá D.C.:

[...] un punto estratégico de la geografía colombiana, debido a que esta zona se convirtió en un territorio propicio para la instalación de la guerra a consecuencia del derrumbe parcial del estado, las dificultades en el acceso terrestre desde la capital del país, la cercanía al poliducto Puerto Salgar-Mancilla y las rutas de salida hacia otros departamentos posibilitando la movilidad de las diferentes fuerzas en disputa, factores que propiciaron que grupos armados como las FARC-EP, los Paramilitares y el Ejército Nacional convirtieran el territorio en un centro de acciones de violencia sistemática. (Fajardo, Liberato y Rodríguez, 2021, 197)

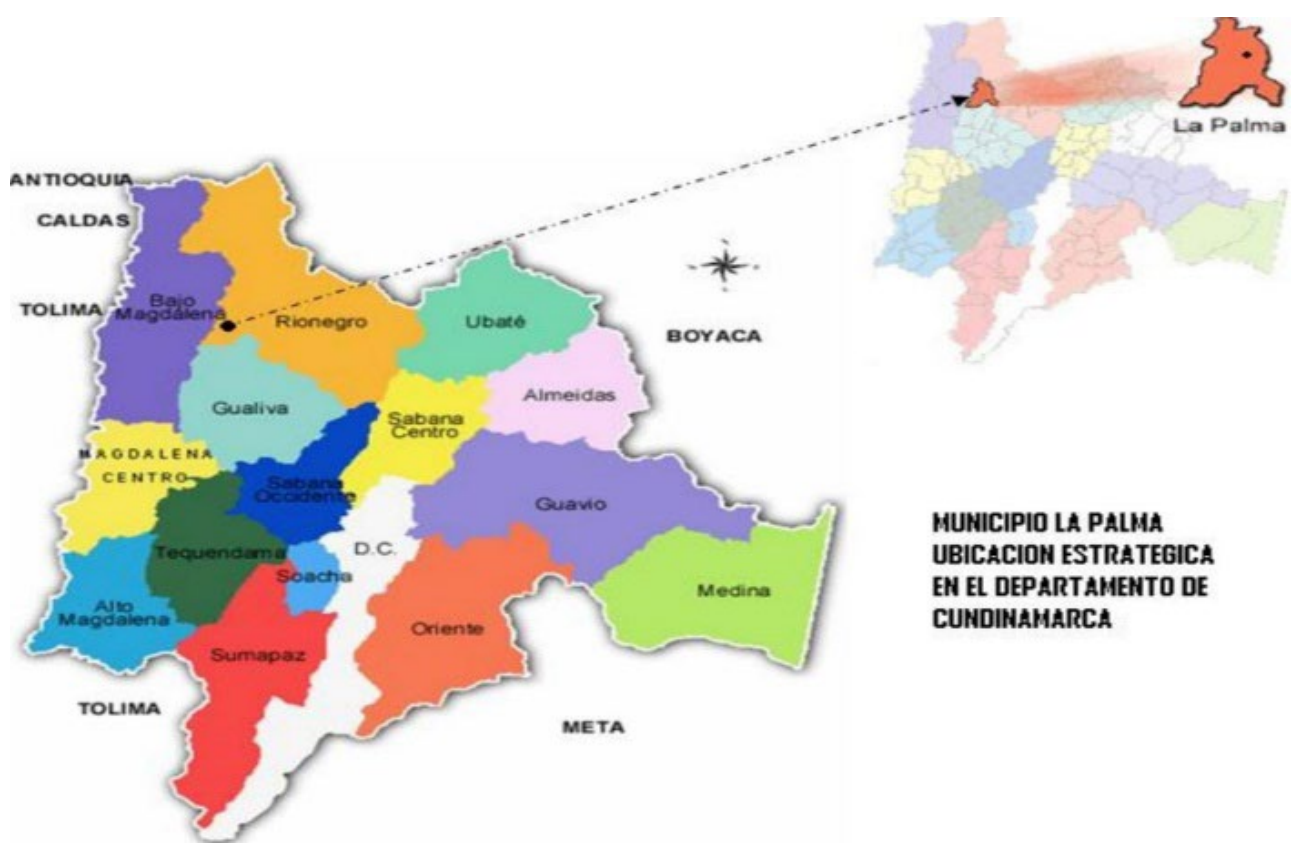

Figura 4. Mapa político de Cundinamarca. Retomado de: http://www.lapalma-cundinamarca.gov.co/municipio/nuestro-municipio. 
En la actualidad, según las proyecciones demográficas del DANE para el 2021, La Palma cuenta con 10.200 habitantes. Estos habitantes se encuentran tanto en la cabecera municipal como en las veredas repartidas en una “extensión de 19.067,34 (Ha), donde 19.001,08 (Ha) son zona rural y 66.26 (Ha) son zona urbana" (Alcaldía Municipal La Palma, 2018).

Esta referencia geográfica de La Palma, y su proximidad con la capital del país, permite evidenciar que la guerra en Colombia no sólo se ha dado en lugares distantes del centro o en zonas selváticas, sino que ha perpetrado diversos lugares del territorio nacional. Por otro lado, permite visibilizar y problematizar el lugar de las víctimas que se encuentran próximas a Bogotá, debido a que en diferentes procesos de cooperación internacional y/o nacional que focalizan como población beneficiaria a víctimas, priorizan comunidades que se encuentran en lugares distantes al centro; con lo anterior, se reafirma la importancia de la comprensión sociogeográfica de los territorios y su relevancia en los procesos de paz, pues "si fueran audaces para reconocer la dignidad en todas las personas y tuvieran la grandeza moral para mostrar que todos debemos cambiar para que todos seamos posibles, sería posible la paz" (De Roux, 2018, 89-90).

Como se ha expuesto hasta este momento, el estudio se focaliza en las Veredas Hinche Alto e Hinche Bajo, que distan a 12 kilómetros de la cabecera del municipio de La Palma, donde residen 300 personas pertenecientes a 85 familias aproximadamente, "contando con una economía agropecuaria basada principalmente en cultivos de plantas como café, cacao, cítricos, plátano, maíz. Su temperatura media es de $21^{\circ} \mathrm{C}$ que la ubica en un clima tropical seco, lo que facilita la producción de los mismos" (Fajardo, Liberato y Rodríguez, 2021, 197).

Como se ha mencionado anteriormente, la población actual que habita este territorio, está constituida principalmente por personas que se reconocen como campesinas y campesinos que dedican su vida a labrar la tierra en cultivos propicios para este territorio como lo son: el café de variedad Santa Isabel, la nacuma y el uso que le dan a la Palma de Iraca, que son correspondientes a la ubicación y a las condiciones geográficas del piso térmico en el cual se ubican, denominado como tropical seco; de allí, obtienen los recursos para su subsistencia. Así pues, "La mayoría de las comunidades campesinas 
de la región tienen una agricultura del pancoger; es decir, que ellos no son grandes empresarios, ni grandes productores, sino que son personas que cultivan para el diario vivir" (entrevista a profesional de la Unidad de Atención y Reparación Integral a las Víctimas, 06 de octubre de 2016).

\section{Contextualización de la guerra en las Veredas Hinche Alto e Hinche Bajo del municipio de La Palma. Entre el miedo y la usurpación de la tierra}

Así como se indicó en el apartado anterior, Colombia ha vivido diferentes tensiones en torno a la propiedad y el uso de la tierra influenciada por intereses internos y externos al país que desde el Siglo XV hasta la actualidad han afectado el proyecto de nación, ya que según refieren Meertens y Sánchez (1983), "sin diferir de otros países latinoamericanos colonizados y saqueados al largo de su historia, siempre fue marcada por el problema de la concentración de la propiedad y del acceso a tierras" (73).

El suceso histórico actual más relevante, ha estado afincado en la guerra que, desde principios del siglo XX, ha detonado la disputa entre movimientos paramilitares, guerrilleros, narcotraficantes y del Estado ${ }^{1}$ :

[...] generada por diversos actores, tales como: el terrorismo de estado orquestado por injerencias de orden político, del personal de las diferentes vertientes de las fuerzas militares, el narcoterrorismo, los grupos paramilitares y guerrilleros de diferentes corrientes ideológicas, ubicados en diferentes latitudes del país; afectando de manera directa e indiscriminada, los territorios rurales, generando daños a las comunidades campesinas. (Rodríguez, Albarracín, Jiménez y Vargas, 2021, 82)

Esta instalación de la guerra se da con mayor intensidad en territorios rurales debido a las características sociogeográficas, así como por los recursos

1. Se comprende por Estado al organismo social y político que comparte un territorio. En el caso de Colombia y según lo que se sostiene en la Constitución Política de 1991, es un Estado Social de Derecho que en su artículo 1 afirma: "Colombia es un Estado social de derecho, organizado en forma de República unitaria, descentralizada, con autonomía de sus entidades territoriales, democrática, participativa y pluralista, fundada en el respeto de la dignidad humana, en el trabajo y la solidaridad de las personas que la integran y en la prevalencia del interés general". 
naturales con los que cuentan; los cuales, se convierten en escenarios de fuego cruzado permanente entre los diferentes actores en disputa por injerencias internas y externas al país a través de estrategias tales como:

La expansión de megaproyectos, generalmente de inversión extranjera, que se ha impulsado bajo la consigna de "generar el desarrollo", provocando también el rechazo de la población campesina e indígena que ha enfrentado la transformación de su entorno, su vida y sus costumbres, sin ninguna consideración humanitaria. (Rubio, 2017, 16)

Estas características de los territorios rurales en Colombia, hacen que surjan intereses políticos y económicos desde diferentes vertientes, pues el agro “fue 'clave' en la definición de las estrategias políticas de desarrollo de la economía nacional y, por ende, los conflictos armados en el campo y la violencia siempre fueron elementos presentes en la historia reciente del país" (Meertens y Sánchez, 1983, 73) que ponen en riesgo la vida rural; sin embargo, en el caso de las veredas Hinche Alto e Hinche Bajo, la identidad campesina se consolida a través de los saberes y prácticas en la tierra, lo que genera un vínculo estrecho con el agro desde una perspectiva de economías campesinas en perspectiva de posdesarrollo, aspecto que Arturo Escobar (2007) profundiza en su libro denominado: "la invención del tercer mundo". Economías que junto con la identidad campesina, han sido amenazadas históricamente por el colapso parcial del Estado al haberse perpetrado en dicho territorio diferentes hechos victimizantes.

En este marco y para el caso específico de Hinche Alto e Hinche Bajo, las acciones de hostigamiento a la población campesina, fueron perpetradas por las diferentes fuerzas en tensión que alteraron la vida social de las personas que habitaban en el territorio. Retomando lo expuesto por Rodríguez, Fajardo, Liberato y Carrera (2021), “entre estas acciones se encuentran: la instalación y enfrentamiento de grupos armados al margen de la ley - despojo de propiedades (década de los 80 hasta 1999), restricción al ejercicio de la democracia (2000)"; intensificándose la violencia durante la primer década del siglo XXI a través de hechos victimizantes registrados en la resolución $\mathrm{N}^{\circ}$ 2014-421756 de 21 de julio de 2014 de la Unidad de Atención y Reparación Integral para las Víctimas donde se refiere que en este territorio se 
presentaron: enfrentamientos armados, ocupación y destrucción de los bienes públicos (ambulancias, puesto de salud, afectación de puentes y quema de volquetas), estigmatización a la población Hinchana por parte de habitantes de otros municipios, homicidios selectivos, actos de tortura y humillación, vinculación de niñas, niños, jóvenes y adolescentes a grupos armados, campos minados y desplazamiento masivo; dicho desplazamiento, generó que las familias buscaran refugio en lo que se consideran espacios seguros como lo son las ciudades capitales de departamento. En este caso en particular, la ciudad más próxima que es Bogotá, lugar al que algunas personas de la población campesina decidieron desplazarse.

La violencia contra la población civil, según lo que se ha identificado en el territorio ha provenido de diferentes fuerzas legítimas (fuerzas militares) y/o ilegítimas (guerrillas, paramilitarismo, narcotráfico), de diferentes corrientes ideológicas validadas (en el caso de las guerrillas influenciadas por corrientes ideológicas como lo son: el comunismo, el socialismo, entre otras; y, el paramilitarismo influenciada por corrientes conservadoras anticomunistas y antisocialistas), apoyadas y/o subsidiadas según sea el caso, por fuentes nacionales y/o internacionales; entre ellas se encuentran: los paramilitares que surgen de lo que históricamente se conoció como los chulavitas y los pájaros de corriente principalmente conservadora de la cual también emergen las Autodefensas Unidas de Colombia (AUC); por otro lado, se evidencia también injerencia de las Fuerzas Armadas Revolucionarias de Colombia Ejército del Pueblo reconocidas a nivel internacional como las FARC - EP, específicamente con el frente 22 de ideologías de izquierda; y por último pero no por ello con menor afectación a la población campesina, el Ejército Nacional de Colombia permeado por la ideología del gobierno de turno.

Parte de lo expuesto se evidencia en lo que sostienen Fajardo, Liberato y Rodríguez (2021) en relación a lo sucedido en las Veredas Hinche Alto e Hinche Bajo.

Fue durante la década de los 80 ' del Siglo XX, cuando el Frente 11 de las FARC-EP pasa a ser el Frente 22, tomando el control de la parte norte del departamento, incluyendo el municipio de La Palma, ejerciendo acciones extorsivas, secuestros y despojos. Así mismo, Gonzalo Rodríguez Gacha comandante militar del Cartel de Medellín, lidera grupos paramilitares en la zona y promueve el cultivo de coca y rutas de tráfico, es así, como los narcoparamilitares y la nar- 
coguerrilla disputan el control territorial de la zona involucrando y violentando a la población civil.

En los años 90' aumenta el reclutamiento forzado de niños y el confinamiento colectivo por parte de las FARC-EP. En 1995 ocurre una masacre en el municipio de La Palma, donde según datos reportados por el Observatorio del Programa Presidencial de Derechos Humanos 14 personas fueron asesinadas. (198).

El recrudecimiento de la guerra en esta tierra del departamento de Cundinamarca, se ve afianzada durante el inicio de la primer década del siglo XXI cuando se generan desplazamientos masivos a la población campesina a través de comunicados que generan miedo y zozobra entre los habitantes, quienes deciden huir al ver en riesgo su integridad física así como su vida, generando "afectaciones en su relación con el territorio que se ven reflejadas en el abandono del campo, la percepción de peligro relacionada con ir a trabajar 'al monte', afectando la actividad productiva y por consiguiente sus ingresos y sostenibilidad" (Jiménez y Montero, 2019, 14).

La consolidación de la guerra, trajo consigo hechos perpetrados desde diferentes frentes, en donde campesinos y campesinas quedaron en medio del fuego cruzado generando afectaciones de diferente índole,situación que se vivió durante décadas partiendo de principios del Siglo XX; y, que fue afianzada entre los años 80's y 90's de dicho siglo e inicios del Siglo XXI, años en los que la guerra se recrudeció (en el caso de los sujetos de reparación colectiva participantes en este proceso investigativo, se evidenció que la guerra se afianzó en la primer década del siglo XXI, bajo el gobierno del ex presidente Álvaro Uribe Vélez ${ }^{8}$ ). (Rodríguez, Albarracín, Jiménez y Vargas, 2021, 90)

En este punto, se desea hacer énfasis en aquellos espacios del territorio que eran lugares de encuentro comunitario y que fueron usurpados por las diferentes fuerzas en tensión alterando el uso de la tierra e incrementando el miedo en la población. Lo sucedido fue registrado en la resolución $\mathrm{N}^{\circ} 2014$ 421756 de 21 de Julio de 2014 por medio de la cual la Unidad de Atención y Reparación Integral a las Víctimas (UARIV), admite a la población de las Veredas Hinche Alto e Hinche Bajo del municipio de La Palma-Cundina- 
marca en el Registro Único de Víctimas a la luz de lo sugerido por la Ley 1448 de 2011, la cual establece:

[...] un conjunto de medidas judiciales, administrativas, sociales y económicas, individuales y colectivas, en beneficio de las víctimas de las violaciones contempladas en el artículo $3^{\circ}$ de la presente ley, dentro de un marco de justicia transicional, que posibiliten hacer efectivo el goce de sus derechos a la verdad, la justicia y la reparación con garantía de no repetición, de modo que se reconozca su condición de víctimas y se dignifique a través de la materialización de sus derechos constitucionales. (Art. 1)

Así, en la Resolución № 2014-421756 de 21 de Julio de 2014 amparada por la Ley 1448 de 2011, se expresan los derechos colectivos que fueron violados por las diferentes fuerzas en disputa en el territorio, haciendo énfasis en este escrito en el que hace referencia a la vulneración por parte de actores armados a bienes públicos protegidos, en donde se sostiene que:

Durante los años en que se recrudeció el conflicto, los grupos armados al margen de la ley utilizaron las ambulancias, el puesto de salud, la escuela y la volqueta, para sus operaciones. La utilización de las escuelas es una práctica común por parte de los grupos armados al margen de la ley, convirtiéndolas en cuarteles, centros de detención, campos de entrenamiento, depósitos de armas y bases para operaciones militares. A menudo, ocupan sólo una parte del colegio, poniendo en grave peligro a los estudiantes que intentan continuar sus estudios. (Resolución N²014-421756, 2014, 3)

De esta manera, la UARIV ${ }^{2}$ confirma la situación vivenciada por la población campesina que habita esta región, en donde fueron apropiados estos bienes por las fuerzas en disputa: las dos sedes de las escuelas ${ }^{3}$, las cuales según lo referencia la comunidad estuvieron por más de 10 años invadidas por los grupos armados. Adicional a estas dos sedes, fue afectado el Alto de la Virgen, el puesto de salud y el polideportivo.

2. Sigla que hace referencia como se había mencionado anteriormente a la Unidad de Atención y Reparación Integral a las Víctimas.

3. En el entorno rural, los colegios son referidos más como escuelas. 
Antes, caminábamos de noche por los caminos sin miedo, con linterna con o sin luna había entre 800 y 600 personas, había de a 30 niños por escuela ahora solo hay 18 en toda la vereda estaban expuestos al reclutamiento forzado, hacían bazares, paseos de ollas comunitarias había mucha y mucha gente para recoger la cosecha en cultivos grandes, habían personas que siempre contrataban a la comunidad para las siembras de cosechas, hoy solo hay cultivos de pan coger y la cosecha de café se perdió. Muchas fincas cambiaron a pastos. (Entrevista a mujer campesina registrada en la Resolución N 2014-421756, 2014, 3)

De lo expuesto con anterioridad, es de donde emerge la necesidad de realizar un proceso de memoria colectiva que se representa "en el interior de esas sociedades [...] y que mantienen por algún tiempo el recuerdo de acontecimientos que sólo tienen importancia para ellas, pero que interesan tanto más a sus miembros cuanto menos numerosos son" (Halbwachs, traducido en Lasén, 1995, 12). Así, la memoria colectiva se recupera a través de un proceso de sistematización a través de diferentes estrategias grupales y comunitarias. En esta ocasión se socializa lo evidenciado a través de la técnica de la cartografía social (ver figura 5), la cual se concibe como:

[...] un lenguaje de representación del espacio geográfico, una forma de abstracción de la realidad; este lenguaje se transmite a través de una forma particular de comunicación iconográfica, el mapa, lo que nos lleva a situarlo dentro de un proceso comunicativo; así como en el discurso hablado prima la voz de la palabra, en el mapa priman las imágenes, los signos y los símbolos se realiza una evaluación del estado actual de estos espacios comunitarios. (Barragán, 2019, p. 142)

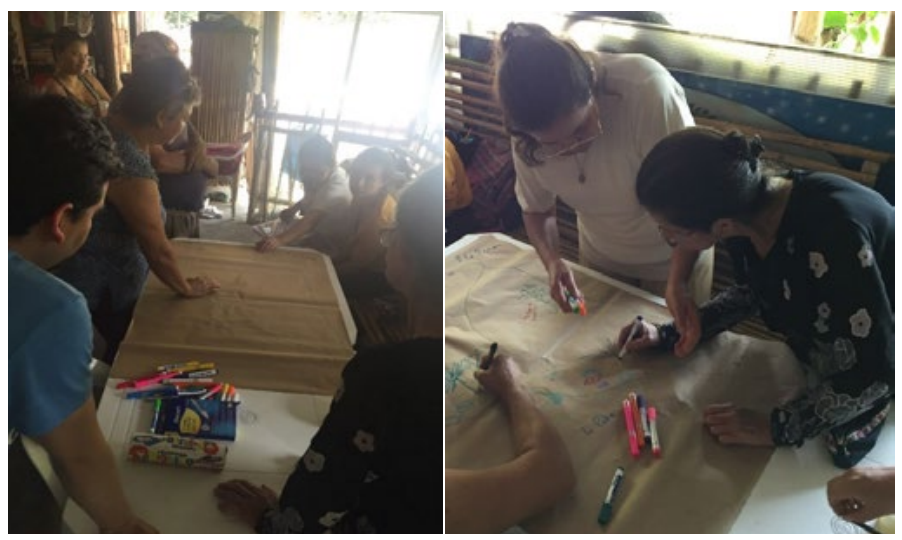

Figura 5. Sistematización a través de la cartografía social. Fuente: Autoría Propia. 
Esta cartografía social permitió hacer un balance de la experiencia a partir de la evaluación del estado actual de bienes públicos, que en su momento fueron afectados por la guerra y registrados en la Resolución $N^{\circ} 2014-421756$ de 21 de Julio de 2014. Estos espacios en el territorio y su recuperación recobran gran relevancia debido a que son los lugares donde la comunidad converge para realizar distintas actividades en correspondencia con su cultura y como escenario de transformación social de los lugares que fueron afectados por la guerra. Ejemplo de ello es el polideportivo, en donde la comunidad desea:

[...] hacer un mural ahí en la casona pero entonces vamos a esperar a ver qué, qué se puede recuperar primero y ahí sí que hagan el mural después, que esté un poquito techado y va a venir también el profesor de deportes a dar deportes a los niños, van a empezar con voleyball y fútbol sala y otros, o sea la idea que se tiene es crear el centro recreocultural de Hinche, o sea como el espacio de cultura, de deporte para que pues todos tengan acceso porque igual no es limitado pa los jóvenes no más sino para todos y buscar la forma de, de qué?, de gestionar un punto de vive digital para que le sirva ahí a toda la comunidad, porque igual si se lleva a la escuela de arriba o a la escuela de abajo los otros no van a tener. (Entrevista a mujeres campesinas, 19 de Junio de 2021).

\section{Caminando la utopía}

El proceso de sistematización de experiencias ha seguido la ruta planteada por Disney Barragán y Alfonso Torres (2017) en su libro: La sistematización como investigación interpretativa crítica, que implica pensar en qué momento es pertinente sistematizar una experiencia, definir unas condiciones iniciales para sistematizarla, conformar el colectivo sistematizador, definir unas preguntas o ejes de sistematización, elaborar el plan de trabajo, reconstruir la narrativa de la experiencia, interpretar críticamente la práctica re-construida, realizar la síntesis y escritura de informes finales, realizar la socializa-acción de resultados y hacer un balance de la experiencia.

En la filosofía de este tipo de investigación, las y los diferentes referentes que la argumentan sostienen que el proceso se desarrolla de manera participativa, donde investigador y población establecen una relación empática, de proximidad, horizontalidad y diálogo permanente. También se menciona 
que el proceso no se desarrolla de manera lineal, sino en espiral: por lo cual, los momentos referenciados con anterioridad pueden darse aleatoriamente a partir del sentir y pensar la experiencia siguiendo los postulados de Fals Borda (1979).

De esta manera, se han generado encuentros grupales a través de técnicas como lo son: la cartografía social en la que se hace énfasis en este escrito; y otras, tales como saberes y sabores, en donde por medio de prácticas de cocina tradicional de la región, se ha recuperado y documentado la Memoria Colectiva, así como por medio de teatro-foro, en espacios de danza contemporánea y en actividades propias de las veredas posibilitando la recuperación de los recuerdos contextualizados en torno al camino de la paz que han recorrido, tal como lo afirman Rodríguez, Albarracín, Jiménez y Vargas (2020):

$[\ldots]$ las acciones populares campesinas [...] trajeron consigo la recuperación y visibilización de los conocimientos situados, de los conocimientos propios de la ruralidad, arraigados a la tierra, que han contribuido a la reinvención de las consecuencias de la guerra. Uno de estos aspectos, está relacionado con tejer vida a partir de la unión y el diálogo vecinal - rural, lo que restaura la confianza en los vínculos entre la población y la recuperación del tejido social generando espacios de sociabilidad y de acción social. (16)

Lo anterior es reafirmado por las mujeres campesinas, quienes sostienen que:

Hemos tejido vida con la unión, con el diálogo, todas las personas, así como ve nos reunimos, hacen una reunión, allá vamos todos. Nos hacen un taller con mucho gusto lo hacemos, nos brindan una ayuda con mucho gusto la recibimos y tenemos cumplir con lo que nos dan. No esperar a que todo nos llueva del cielo, trabajar, a seguir adelante y trabajar porque si nos estamos así (manos cruzadas) todos los días toca es trabajar. (Entrevista Grupal a mujeres campesinas, junio 01 de 2018)

Estas reflexiones, han sido recuperadas por el colectivo sistematizador, el cual está conformado por tres mujeres habitantes de las veredas Hinche Alto e Hinche Bajo; dos de ellas, personas en edad adulta con bachillerato incompleto y una joven que se encuentra cursando estudios universitarios en 
modalidad a distancia. El colectivo sistematizador lo complementa el autor del presente escrito quien se encuentra en formación doctoral. Al interior del grupo, se han generado los espacios de debate para la focalización del proceso en donde "los ejes en torno a los cuales se focaliza la reconstrucción del pasado son los desafíos que el colectivo define frente a su práctica desde su presente y frente a sus visiones de futuro (utopías viables)" (Barragán y Torres, 2017, 90).

A partir de este proceso, y teniendo presente lo mencionado con anterioridad, el balance de la experiencia en torno a la situación actual de los bienes públicos a través de la cartografía social permite identificar tal como se evidencia en la figura 6, que han sido recuperadas las dos sedes de la escuela en donde a partir de procesos de gestión por parte del grupo de mujeres tejedoras, se han logrado mejoras en la planta física y equipamiento con material pedagógico. Por otra parte, se ha recuperado el Alto de la Virgen, lugar de encuentro para actividades religiosas y que recobra una gran importancia para la comunidad debido a que la mayoría de la población se reconoce como católica. Al lado de la Virgen y con acompañamiento de la Unidad de Atención y Reparación Integral a las Víctimas (UARIV), se logró construir el jardín de la memoria:

[...] se evidenció la creación y reinvención por parte de las lideresas, de espacios micro políticos, a través de la recuperación de los lugares de encuentro vecinal y de vida rural, entre las que se encuentran: constitución de juntas de acción comunal, grupos culturales, recuperación de conmemoraciones en torno a las creencias y costumbres de la población y el territorio; han gestionado la reconstrucción de escuelas para niños y niñas, canchas de fútbol, iglesias y puntos de congregación; en donde en algunos casos, se han erigido jardines de la memoria, visibilizando mujeres resistentes. (Rodríguez, Albarracín, Jiménez y Vargas, 2020, 18). 

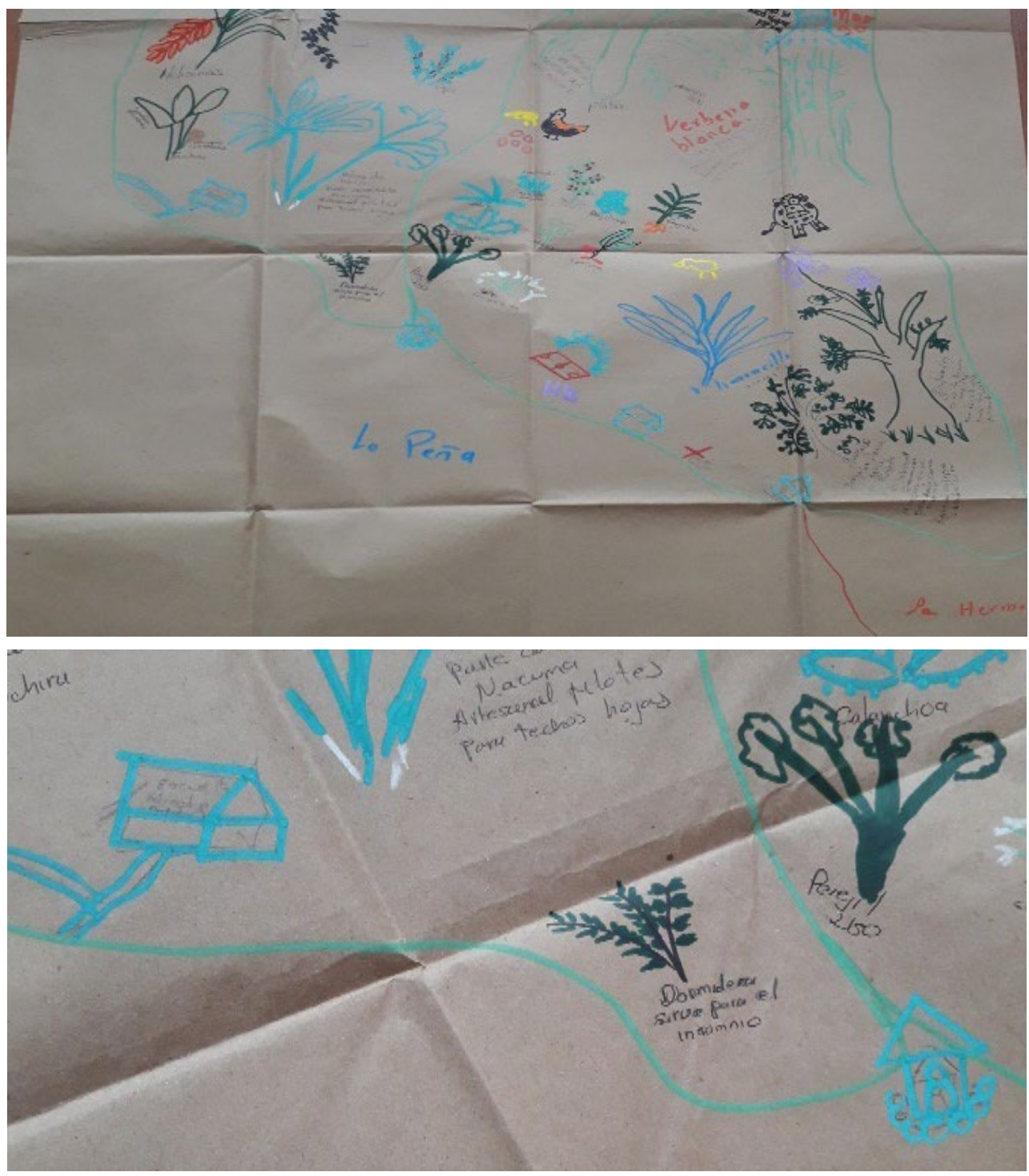

Figura 6. Cartografía social. Lugares recuperados en color verde. Fuente: Autoría Propia.

Cabe exaltar en este punto, la capacidad de agenciamiento de las mujeres campesinas de las veredas Hinche Alto e Hinche Bajo, quienes, a partir de su deseo de forjar paz en el territorio, regresaron al mismo sin respaldo estatal y existiendo aún presencia de las diferentes fuerzas armadas en disputa, progresivamente, se involucraron en procesos de capacitación y gestión que han permito ir transformando los espacios comunes: 
[...] participo de muchos talleres que logra la Sra. M, ella es la que, como es del comité, es la que va a Bogotá, va a sus reuniones, ella pide y lo que le aprueban llega a la gente le colabora, todo eso viene en nombre de lo que ella solicita para la comunidad, entonces nos están dando todos estos programas como están ustedes y otros programas. (Entrevista Grupal a mujeres campesinas, 01 de junio de 2018)

En contraste con los bienes comunitarios recuperados, se encuentran los que aún se encuentran sin recuperar y que en la figura 7 se identifican en color rojo; ellos son: el centro de salud, el cual se encuentra en condiciones muy precarias unido a que se encuentra en un terreno con falla geológica; $y$, a lo que la comunidad llama polideportivo, bien público en el cual en este momento se han enfocado los esfuerzos para su recuperación, que consisten en: la clarificación de la titulación del predio - gestión que se adelanta en conversaciones con el alcalde del municipio, la gestión de recursos a través de presentar proyectos de cooperación internacional, así como por aportes de la comunidad tanto con recursos económicos como humanos.

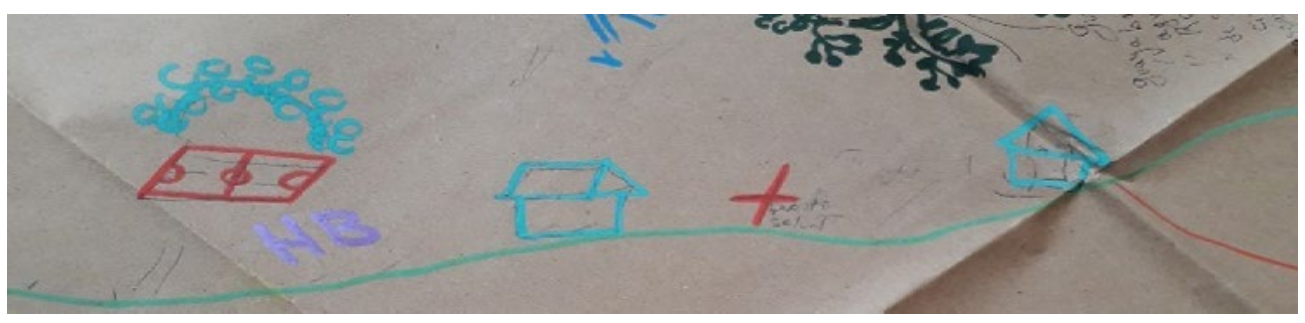

Figura 7. Cartografía social. Bienes públicos por recuperar. En color rojo. Elaboración: Autoría propia.

El polideportivo se concibe por parte del equipo sistematizador como el espacio de mayor necesidad por recuperar, debido a que en la sistematización de la experiencia de saberes campesinos a través de un proceso de memoria colectiva emergió una nueva situación que se vincula a que la memoria se ha ido reconstruyendo pero no hay relevo generacional en el territorio debido a que las y los jóvenes huyendo de la guerra han migrado a Bogotá para salvaguardar su vida y/o para encontrar oportunidades de formación universitaria-laboral de la que carecen en el territorio; por ende, no hay a quién trasmitir la memoria, pues la mayoría de las personas que habitan las veredas son 
personas mayores y hay un vacío en el ciclo vital de jóvenes, debido a que la mayoría de ellas y ellos fueron desplazados cuando niños a la ciudad y ya no regresaron; y los que están — en su mayoría — desean migrar a la capital por falta de oportunidades de formación técnico-profesional y laboral, tal como lo afirman personas de la comunidad.

Los jóvenes son muy pocos y los niños también es un rango muy pequeño, porque la violencia lo que hizo es que todos los jóvenes se quedaran en las ciudades" (entrevista a mujer campesina, 01 de junio de 2018); y segundo, por la falta de oportunidades laborales y/o educativas, "de trabajo, los jóvenes no quieren volver porque no tienen oportunidades de trabajo. (Entrevista a mujeres campesinas, 26 de octubre de 2016)

Acá en La Palma podemos decir que tenemos un $80 \%$ de población de adultos mayores. (Entrevista a mujer campesina, 01 de junio de 2018)

Hacen falta muchas cosas porque como tú ves el territorio es muy extenso, las necesidades de cada una de las personas son diferentes, hay población que en este momento ya están saliendo de bachillerato pero no hay alternativas para que ellos se queden acá, el problema nuestro es que no tenemos fuentes de empleo para que los jóvenes sigan haciendo ese relevo generacional y se queden en el campo, la mayoría de jóvenes terminan su bachillerato y se van a la ciudades, estamos perdiendo ese relevo generacional. (Trabajo de campo, 2018)

De esta manera, la recuperación del polideportivo (ver figura 8) se convierte en la visión de futuro (la utopía posible) de la que se habla en la sistematización de experiencias y que las mujeres han decidido denominar: "Hinche territorio de paz, centro de saberes campesinos". Un espacio que a partir de la cooperación nacional e internacional, pretende convertirse en un proyecto autosostenible en donde se puedan desarrollar procesos: de formación técnico-profesional relacionados con saberes del campo (universidad campesina), de emprendimiento a partir de procesos de economía circular y soberana (alternativas laborales), de actividades deportivas y culturales (campeonatos y proyectos artísticos), así como la creación del primer centro de memoria de la región en correspondencia con las expectativas y los deseos que residen en las vidas de la población, especialmente en las y los jóvenes.

Figura 8. Estado actual del polideportivo. La utopía. Fuente: Autoría propia. 
A partir de lo expuesto, el proceso de sistematización de experiencias ha permitido recuperar a través de las voces de las mujeres campesinas la his-

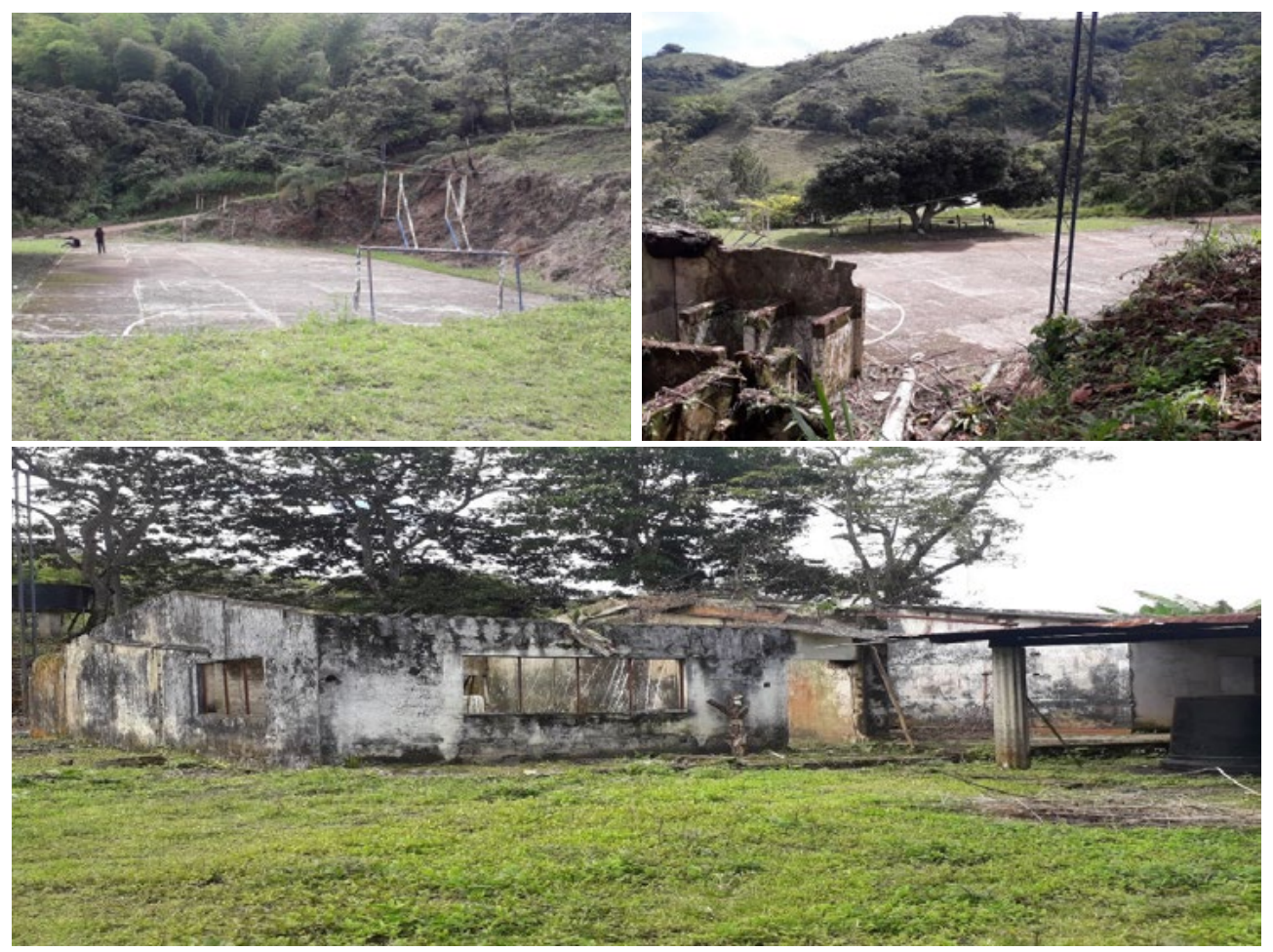

toria que se ha circunscrito en las Veredas Hinche Alto e Hinche Bajo del municipio de La Palma-Cundinamarca en Colombia, territorio que desde la década de los 80 hasta la primera década del siglo XXI, experimentó diferentes hechos victimizantes.

Ha sido a través del agenciamiento de las mujeres, al resistir desde el momento en que decidieron regresar sin respaldo estatal y aún con la presencia de las fuerzas en disputa, que han logrado recuperar la tierra y los lugares de encuentro comunitario a partir de la unión, el diálogo, la participación y la gestión, así como del trabajo en el campo a partir de la siembra de café, de procesos de panadería, de artesanía y del uso versátil de los frutos que se circunscriben en un clima de trópico seco que en este territorio de manera particular son la Palma de Iraca y la Nacuma. A partir de estos saberes y prácticas es desde donde estas mujeres desean consolidar el proyecto denominado: Hinche Territorio de Paz, Centro de Saberes Campesinos, como experiencia de construcción de paz y reconstrucción de tejido social, resignificando los lugares de la guerra por territorios de paz. 


\section{Referencias:}

Alcaldía Municipal La Palma Cundinamarca. 2018. Mapa distribución política de Cundinamarca [Imagen]. Tomada de: http://www.lapalma-cundinamarca.gov.co/municipio/nuestro-municipio

Alcaldía Municipal La Palma. 2018. Nuestro municipio. Recuperado de: http://www.lapalma-cundinamarca.gov.co/municipio/nuestro-municipio

Arévalo Robero, Melissa, Diana Bernal Chala, Lucy Quiñones Caicedo, Miguel Rodríguez Suárez i Michel Tarazona García. 2018. Cuerpo presente: una comprensión desde la danza contemporánea y el Trabajo Social. Cartilla pedagógica.

Barragán Cordero, Disney i Alfonso Torres Carrillo. 2017. La sistematización como investigación interpretativa crítica. Bogotá: Editorial El Buho.

Barragán León. Andrea. 2019. Cartografia Social: lenguaje creativo para la investigación cualitativa. Sociedad y Economía (36).

Barrero Zabaleta, Juan. 2017. Geografía Física de Colombia. Bogotá: Fundación Universitaria del Área Andina.

Bejarano, Ana i Eduardo Pizarro. 2010. Colombia: el colapso parcial del Estado y la emergencia de los "protoestados. En L. Orjuela (Ed.), El estado en Colombia (pp. 384 - 412). Bogotá: Ediciones Uniandes.

Benseny, Graciela. 2020. Visión Geográfica del Continente Americano. Mar del Plata: Universidad de Mar del Plata.

Cepeda, Carolina. 2019. Colombia, América del Sur y el Nuevo Panorama Político Electoral. Buenos Aires: Pensamiento Propio.

CONETS. (2016). Sujetos de Reparación Colectiva y construcción de territorios de paz en el marco de la Ley 1448 del 2011. (Proyecto de Investigación). Entrevista Grupal 2 [En Persona]. (2017). La Palma, Cundinamarca.

CONETS. (2016). Sujetos de Reparación Colectiva y construcción de territorios de paz en el marco de la Ley 1448 del 2011. (Proyecto de Investigación). Entrevista Grupal 3 [En Persona]. (2018). La Palma, Cundinamarca.

CONETS. (2016). Sujetos de Reparación Colectiva y construcción de territorios de paz en el marco de la Ley 1448 del 2011. (Proyecto de Investigación). Entrevista Grupal 9 [En Persona]. (2016). La Palma, Cundinamarca. 
Defensoría del Pueblo Colombia. 2018. Informe especial: economías ilegales, actores armados y nuevos escenarios de riesgo en el posacuerdo. Bogotá: Icolgraf Impresores S.AS.

Departamento Administrativo Nacional de Estadística - DANE. 2018. Resultados Censo Nacional de Población y Vivienda 2018. Recuperado de: https://www.dane.gov.co/index.php/estadisticas-por-tema/demografia-y-poblacion/censo-nacional-de-poblacion-y-vivenda-2018.

De Roux, Francisco. 2018. La Paz Imperfecta. Bogotá: Editorial Planeta Colombiana, S.A.

Elboj Saso, Carmen i Jesús Gómez Alonso. 2001. El giro dialógico de las Ciencias Sociales: hacia la comprensión de una metodología dialógica. Revista de Gestión Pública y Privada No. 8 (2003).

Jiménez Ahumada, Rosa i Amaury Monterio Ramírez. 2019. Aportes de la Estrategia Entrelazando en la reconstrucción del tejido social en el sujeto de reparación colectiva Zipacoa. En: R. Salamanca, (Ed.), Sujetos de Reparación Colectiva y Construcción de Territorios de Paz. Libro 1: Comunidades campesinas en Colombia: contextos de guerra y sujetos de reparación colectiva (pp. 325 - 352). Bogotá: Universidad Externado de Colombia.

Lásen Díaz, Amparo. 1995. Halbwachs La mémoire collective, París, PUF, 1968. Traducción.

Ley No. 1448. Bogotá, Colombia, 10 de junio de 2011.

Liberato Ángela, Laura Fajardo y Miguel Rodríguez. 2021. "Tensiones en la implementación de la Estrategia Entrelazando en el Sujeto de Reparación Colectiva de las veredas Hinche Alto e Hinche Bajo en el municipio de La Palma - Cundinamarca en el marco de la Ley 1448 del 2011". Trabajo Social 23 (2): 193-217. Bogotá: Departamento de Trabajo Social, Facultad de Ciencias Humanas, Universidad Nacional de Colombia. doi: 10.15446/ts.v23n2.90283

Meertens, Donny i Gonzalo Sánchez. 1983. Bandoleros, Gamonales y Campesinos. El caso de la violencia en Colombia. Bogotá: El Ancora Editores.

Mellizo, Wilson i Alba Lucía Cruz. 2019. El Dorado (Meta), lógicas de la guerra y reparación colectiva en el piedemonte llanero (pp. $58-$ 107). En: R. Salamanca, (Ed.), Sujetos de Reparación Colectiva y Construcción de Territorios de Paz. Libro 1: Comunidades campesinas en Colombia: contextos de guerra y sujetos de reparación colectiva (pp. 31 - 85). Bogotá: Universidad Externado de Colombia.

Méndez Reyes, Johan. 2008. Memoria individual y Memoria colectiva: Paul Ricoeur. Trujillo: Ágora. 
Oficina de Información Diplomática. 2021. Colombia. República de Colombia. Retomado de: http://www.exteriores.gob.es/documents/ fichaspais/colombia_ficha\%20pais.pdf._Consultado el 10 de Noviembre de 2021.

Ramírez, Juan i De Aguas, Johan. 2016. Configuración territorial de las provincias de Colombia. Ruralidad y Redes. Naciones Unidas.

Rodríguez Suárez, Miguel, Anderson Esteban Albarracín-Castañeda, Lina Mayerly Jiménez-Rodríguez i Giselle Natalia Vargas-Páez. Agenciamiento de comunidades campesinas en Colombia. En: César Carrera e Isabel Zolysko, (Eds.), Sujetos de Reparación Colectiva y Construcción de Territorios de Paz. Libro 1. Bogotá: Universidad Externado de Colombia.

Rodríguez Suárez, Miguel, Laura Fajardo Ramírez, Ángela Liberato López i Patricia Carrera Díaz. 2021. Veredas Hinche Alto e Hinche Bajo: sinergias y tensiones en los caminos trazados para forjar territorio de paz. El poder de un pueblo que teje vida. En W. Mellizo y M. Rojas (Eds.), Sujetos de Reparación Colectiva y Construcción de Territorios de Paz. Libro II:. (pp. 128-199). Bogotá: Universidad Externado de Colombia.

Rodríguez Suárez, Miguel, Anderson Esteban Albarracín-Castañeda, Lina Mayerly Jiménez-Rodríguez i Giselle Natalia Vargas-Páez. 2021. Capacidad de creación y reinvención de las comunidades campesinas en medio del colapso parcial del Estado. La experiencia de los sujetos de reparación colectiva en Colombia. Revista Eleuthera, 23(2), 15-37. http://doi.org/10.17151/eleu.2021.23.2.2.

Rodríguez Suárez, Miguel. 2021. SABERES CAMPESINOS QUE FORJAN TERRIORIOS DE PAZ EN MEDIO DEL COLAPSO PARCIAL DEL ESTADO EN COLOMBIA. Memoria colectiva en las Veredas Hinche Alto e Hinche Bajo del Municipio de La Palma - Cundinamarca a través de las voces de campesinas y campesinos que tejen paz (Tesis Doctoral). Entrevista Grupal 2 [En Persona]. (2021). La Palma, Cundinamarca.

Rubio Vega, Blanca. 2017. El movimiento campesino en América Latina durante la transición capitalista, 2008 - 2016. Revista de Ciencias Sociales No. 31.

Unidad para la Atención y Reparación Integral de las Víctimas. Resolución $\mathrm{N}^{\circ}$ 2014-421756. 2014. Colombia.

UNISDR. 2015. América del Sur. Enfoque para la gestión del riesgo de desastres. 
